\title{
The Relationship Between EFL Learners' Resilience and Autonomous Learning
}

\author{
Parinaz Kajabadi \\ Department of English Language Teaching, Islamic Azad University, Shahre Qods Branch, Tehran, Iran \\ E-mail: Parinaz.kaj@gmail.com \\ Reza HajiMohammadi (Corresponding author) \\ Department of English Language Teaching, Technical and Vocational University, Tehran, Iran \\ E-mail: Rezalincoln@yahoo.com \\ Pantea Pahlavani \\ Department of English Language Teaching, Islamic Azad University, Qazvin Branch, Qazvin, Iran
}

Received: 03-03-2016

Published: 01-07-2016
Accepted: 06-05-2016

doi:10.7575/aiac.ijalel.v.5n.4p.163
Advance Access Published: May 2016

URL: http://dx.doi.org/10.7575/aiac.ijalel.v.5n.4p.163

\begin{abstract}
This study aimed to investigate relationship between resilience as a personality factor defined in positive psychology and autonomous learning as a newly developed subject in learning and teaching (EFL area). This research employed resilience scale by Connor and Davidson (2003) and learner autonomy questionnaire by Spratt, Humphreys and Chan (2002) to evaluate EFL learners' resilience level and their autonomy. To meet the purpose of this study, about 150 male and female participants randomly selected among undergraduate students majoring English language translation. Collected data of two questionnaires were analyzed through Spearman's correlation and regression. Findings of the correlation analysis revealed that there is a significant relationship between resilience and autonomy $(\rho=.29, n=156, p$ $<.01)$. Also, results showed that resilience is a strong predictor for autonomous learning.
\end{abstract}

Keywords: Autonomy, Resilience, Positive Psychology, EFL learners, Education

\section{Introduction}

Majority of teaching methods till now considered language learners as passive and dependent individuals who cannot "control their own learning progress" (Rivers, 1992; Holder \& Usuki, 1999; Cited in Negari \& Solaymani, 2013). But in recent decades autonomous learning has became more popular among scholars and educators. Holec (1995) refers to autonomy as an individual's ability and his previous experience to feel responsible for his own learning. He delineates autonomy as an " ability to take charge of one's own learning where to take charge of one's learning is to have and hold the responsibility for all the decisions concerning all aspects of this learning" $(1981, \mathrm{p} .3)$. He perceives ability and responsibility as operating in the following areas: specifying objectives, contexts and progressions of learning, choosing methods and techniques to meet the objects, monitoring the procedure of acquisition and finally evaluating what was the outcome (Holec, 1995). In addition, Nation and Macalister (2010) believe that becoming effective and independent language learner needs a learner to be autonomous. They postulate autonomy as the "ability to know how to learn a language and how to monitor and be aware of their learning" (p. 38). Benson (2001) states that the improvement of an autonomous leaner leads him/her to a better language learner.

It is a long time since the subject of good language learner came into consideration and scholars looking for good language learner characteristics. Rubin and Thompson (1982; Brown, 2007) discussed language learner characteristics, which include high self-confidence to take responsibility of their own learning. On the other hand, research areas in the field of educational psychology are engaged with investigation of "complexity of learning" and "learner characteristics" through various settings (Reynolds \& Miller, 2003). In line with educational psychology, other concepts emerged as positive psychology, which includes a series of components such as resilience, courage, mindfulness, compassion, creativity, curiosity, self-control, and well-being that to some extend were investigated in educational study as well as in EFL area. Resilience is a new subject in the realm of teaching and learning second language and has been defined as "stress-coping ability" (Connor \& Davidson, 2003, p.77). Generally resilience is defined as individuals' capability to bounce back from adversities and adapt to their environment (Wagnild \& Collins, 1993). In the academic context Martin and Marsh (2006) defines academic resilience as "a student's ability to effectively deal with setbacks, challenges, adversity and pressure in the academic setting (Martin \& Marsh, 2006; cited in Abram-Terry, 2014, p.34). Wang (2009) construes resilience as "a key variable associated with the adaptation to the university environment" (p. 20). Several researches in this area revealed that resilience could reduce stress; help with management of academic demands; increases academic success, and also facilitates process of coping with academic pressures (Abbott, Klein, Hamilton \& Rosenthal, 2009; Bovier, Chamot \& Perneger, 2004). Resilience is a developmental notion that 
demonstrates an individual's ability to recuperate from adversity and stress (Reivick \& Shatte, 2002, cited in Chambers, Brawley \& Castille, 2012). Some definitions of "academic resilience" refer to "positive adaptation" (Terry, 2014). Kobasa (1979) believes that resilience people have two main features; they own the sense of commitment, and they have capability to recognize limits to control them. Also, many scholars consensus that academically resilient English learners may have several characteristics such as consider their future plans realistically, have the ability to communicate effectively, accept responsibility for themselves and their own behavior (Bernard, 1993; Clark \& Clark, 1984; Garmezy, 1985; Werner \& Smith, 1982).

So, based on definition of autonomous learning and definition of resilient learner in academic context, it can be inferred that improving resiliency in English learners may help learners to be more autonomous in their learning process. Following to importance of resilience in education and learning and development of autonomy in recent learning pedagogies the researchers persuaded to investigate relationship between resilience and autonomous learning. As resilience has been studied in ESL and EFL area before, it leaded the researchers to propose these questions as follows to scrutiny the relationship of resilience as a personality factor with autonomy.

Research Question 1: Is there any significant relationship between the resilience level of EFL learners and autonomous learning?

Research Question 2: Is EFL learners' resilience level a strong predictor of their autonomous learning?

To find the answer for the abovementioned questions, following null hypothesis were proposed:

1. H0: There is no significant relationship between resilience level of EFL learners and their autonomous learning.

2. H0: EFL learners' resilience level is not a strong predictor of their autonomous learning.

\section{Method}

\subsection{Participants}

A sample of 156 male and female participants among undergraduate students of Islamic Azad University majoring English Language Translation was randomly selected. The researcher applied cluster sampling to select a group of individuals who are representative of EFL learners. The researcher did not consider any criterion for homogeneity due to the nature of correlational study. Participants were selected among university students majoring English translation, which English was not their first language. The age range of participants was above 18.

\subsection{Instruments}

To accomplish the purpose of the study, the researchers applied two psychological and educational questionnaires as follows:

1) The questionnaire of resilience developed by Connor and Davidson (2003) to measure resilience level of participant facing adversary situations.

2) The questionnaire of autonomy by Spratt, Humphreys, and Chan (2002) to evaluate how autonomously participants learn English as a second language.

\subsubsection{Resilience Scale}

Resilience scale developed by Connor and Davidson (2003), comprises 25 items, each bears 4-point range answers as not true at all (0), rarely true (1), sometimes true (2), often true (3), and true nearly all of the time (4). The total score for items is from 0-100. The scale of Connor and Davidson developed based on the feelings over the past month (Connor and Davidson, 2003). Connor and Davidson (2003) summarize the most prominent characteristics of resiliency as ability to cope with challenges and adopt to changes; ability to look at bright side of each situation and able to bounce back after any adversary; preferring to be master of problem solving and able to make difficult decisions; believing in his/her goals and his own abilities and at the end is proud of his/her achievements.

\subsubsection{Learner Autonomy Questionnaire}

Questionnaire of learner autonomy designed by Spratt, Humphreys, and Chan (2002) was employed in this study. Spratt et al. questionnaire got a strong influence from Holec (1981) definition of autonomy. He defined autonomy as ability to take charge of one's own learning, which includes making decisions regarding all steps of learning process. And he assumed this ability within five scopes: specifying objectives, specifying contexts, methods and techniques to be used, overseeing process of acquisition, and evaluation of whatsoever has been learned. The questionnaire is a likert-type, 52 items. It consists of four sections. Sections 1 to 3 evaluate students' responsibilities, confidence and motivation relating to learning and last part mainly investigates students' level of autonomous learning inside and outside the classroom. Each item carries 5-point range respond as follows: not at all (1), a little (2), some (3), mainly (4), and completely (5) for first part. Very poor (1), poor (2), ok (3), good (4), very good (5) for section two and point 5 to 1 for choices in motivation part (section 3). And for last part never (1), rarely (2), sometimes (3) and often (4). So, the total score may vary from 52 to 233 based on the scoring.

\subsection{Procedure}

In order to accomplish the purpose of the research and answering the research questions, the researcher proceeded the following steps: first, researchers piloted Persian version of two questionnaires of resilience and autonomy to 30 English leaners (Islamic Azad University students) who almost had the same characteristics of main participants. Second, the researchers briefed the process of answering questionnaires and nature of the study to participants and 
emphasized the authenticity of the answers. It was also clarified that results and findings of the questionnaires shall be applied merely for the purpose of the study and all the answers shall be kept confidently. All the participants admitted their consent to take part in the study. Then, resilience scale by Connor \& Davidson (2003) distributed among the participants and allocated 10 minutes to answer 25 items and after that at the same session questionnaire of autonomy by Spratt et al. (2002) asked to be answered within 20 minutes. As the resilience scale by Connor \& Davidson developed in English for native speakers, the researcher utilized the Persian version of questionnaire. Jokar et al. (2007) calculated reliability of the scale through Chronbach's alpha analysis to be .73. Reliability of the questionnaire through Chronbach's alpha analysis in this study estimated to be 0.82 . The Persian version of learner autonomy questionnaire developed by Spratt, Humphreys, and Chan (2002) has been translated and validated by Fahim and Behdani (2011). Reliability of the questionnaire through Chronbach's alpha analysis in this study estimated to be 0.8 .

The researcher analyzed the quantitative data through statistical procedure to find whether there is any significant relationship between EFL learners' resilience and their autonomy. And, after that predictability of resilience was investigated.

\section{Data Analysis Procedure}

\subsection{Results}

Current study considered descriptive research since there is not any treatment and also a correlational research as this study aimed to answer the questions through inspecting the existing relationship between the variables. In the present study, researchers employed both descriptive and inferential data analysis to answer the proposed questions. First, researchers performed some preliminary analyses to determine the legitimacy of running the analyses along with the type of statistical techniques, i.e. parametric or non-parametric. Also, in order to check some other significant assumptions through inspecting the features of the data following assumptions were checked; a) linear relation between each pair of variables; b) homoscedasticity, and C) normality of the distribution of variables. For descriptive analysis mean, standard deviation, and standard error of the mean was provided.

To check linearity of relations the researchers created a multiple scatterplot. And, linearity of relations was confirmed. The distribution of scores was not funnel shape; therefore, the assumption of homoscedasticity was met for these variables. In order to check the normality of the distributions, first the descriptive statistics of the data were obtained and kurtosis and skewness ratios were calculated. Then, the Kolmogorov-Smirnov test was run as a further attempt to inspect the normality of the distributions.

Table 1. Descriptive Statistics of the Scores

\begin{tabular}{lcccccccccc}
\hline & \multicolumn{4}{c}{ N } & Mean & SD & \multicolumn{3}{c}{ Skewness } & \multicolumn{3}{c}{ Kurtosis } \\
\cline { 2 - 10 } & \multicolumn{1}{c}{ Statistic } & Statistic & Statistic & Statistic & Error & Ratio & Statistic & Error & Ratio \\
\hline Autonomy & 156 & 181.314 & 24.9117 & -.361 & .194 & -1.86 & -.145 & .386 & -.37 & .06 \\
Resilience & 156 & 65.840 & 16.3737 & -.485 & .194 & -2.5 & .024 & .386 & .06 \\
Valid N (listwise) & 156 & & & & & & & & & \\
\hline
\end{tabular}

As demonstrated in Table 1., the distribution for the scores of autonomy was normal as both skewness ratio and kurtosis ratio values fell within the range of -1.96 and +1.96 . This point supports the normality of distribution for autonomy scores (Tabachnick \& Fidell, 2007). However, for resilience only the kurtosis ratio values fell within the abovementioned range, and the skewness ratio values were beyond the critical \pm 1.96 value. So, the normality of resilience could not be confirmed. Then, in order to examine the normality of the distributions further, KolmogorovSmirnov test was run (Table 2.).

Table 2. Tests of Normality of the Scores

\begin{tabular}{lccccccc}
\hline & \multicolumn{3}{c}{ Kolmogorov-Smirnov $^{\mathrm{a}}$} & \multicolumn{3}{c}{ Shapiro-Wilk } \\
\cline { 2 - 7 } & Statistic & $\mathrm{df}$ & Sig. & Statistic & $\mathrm{df}$ & Sig. \\
\hline Autonomy & .057 & 156 & $.200^{*}$ & .986 & 156 & .129 \\
Resilience & .085 & 156 & .008 & .979 & 156 & .018 \\
\hline
\end{tabular}

As presented in Table 2, the Sig. values for resilience score was less than .05. And it suggests that the assumption of normality is violated for resilience; however, as the Sig. value for autonomy scores is significantly higher than the resilience value (.05), the normality of distribution for autonomy scores is supported. Considering all abovementioned results through preliminary and descriptive analysis the researchers concluded that the data do not meet the assumptions of parametric statistical techniques. Therefore, the related research questions were answered through employing nonparametric tests. In order to answer the proposed questions, Spearman's correlation employed. 
First Null Hypothesis: HO: There is no significant relationship between resilience level of EFL learners and their autonomous learning.

In order to answer this question, the data were analyzed using the Spearman rank order coefficient of correlation. Results of analysis revealed that there was a significant and positive correlation between resilience and autonomy, $\rho=$ $.29, n=156, p<.01$, and high levels of autonomy were associated with high levels of resilience. This signified a smallto-medium effect size supplemented by a small confidence interval $(0.14-0.427)$. Thus, the first null hypothesis was rejected.

Since a significant relationship between resilience and autonomy observed, it was legitimate to run a multiple regression in order to answer the second research question of this study.

Second Null Hypothesis: HO: EFL learners' resilience level is not a strong predictor of their autonomous learning.

Table 3. Regression Output: ANOVA

\begin{tabular}{llccccc}
\hline Model & & Sum of Squares & df & Mean Square & F & Sig. \\
\hline 1 & Regression & 14302.969 & 2 & 7151.485 & 13.362 & $.000^{\mathrm{b}}$ \\
& Residual & 81888.640 & 153 & 535.220 & & \\
& Total & 96191.609 & 155 & & & \\
\hline
\end{tabular}

a. Dependent Variable: Autonomy

b. Predictor: (Constant), Resilience

Table 3 reports the results of ANOVA $(F(2,153)=13.3, p=0.0005)$, the results of which were considered significant. This means that the model can significantly predict EFL learners' autonomy.

Table 4. Regression Output: Coefficients

\begin{tabular}{|c|c|c|c|c|c|c|c|}
\hline \multirow{2}{*}{\multicolumn{2}{|c|}{ Model }} & \multicolumn{2}{|c|}{$\begin{array}{l}\text { Unstandardized } \\
\text { Coefficients }\end{array}$} & \multirow{2}{*}{$\begin{array}{c}\begin{array}{c}\text { Standardized } \\
\text { Coefficients }\end{array} \\
\beta\end{array}$} & \multirow[b]{2}{*}{$\mathrm{T}$} & \multirow[b]{2}{*}{ Significance } & \multirow[b]{2}{*}{ Part Correlation } \\
\hline & & B & $\mathrm{SE}$ & & & & \\
\hline \multirow[t]{2}{*}{1} & (Constant) & 134.589 & 9.265 & & 14.526 & .000 & \\
\hline & Resilience & .439 & .117 & .288 & 3.745 & .000 & .279 \\
\hline
\end{tabular}

Table 4 demonstrates the standardized Beta Coefficients which signify to what degree resilience contributes to the prediction of the autonomy. The inspection of the Sig. values showed that resilience as predictor variable make statistically significant contributions to the equation as its Sig. values is less than .05. The comparison of $\beta$ values revealed that resilience has the large $\beta$ coefficient $(\beta=0.288, t=3.745, p=0.0005)$. Therefore, it was concluded that resilience could predict significantly the autonomy scores of the candidates. The inspection of part correlation (semipartial correlation coefficient) revealed that resilience uniquely explains 7.7 percent of the variance in autonomy $(.279 \times .279=.077)$. Thus, the second null hypothesis of the study was rejected.

\section{Discussions and Conclusion}

Resilience is an ability to cope with stress successfully (Connor \& Davidson, 2003). It has been a while that scholars got interested in resilience as a personality and psychological factor which showed its impact on learning and academic contexts. As Martin and Marsh (2006) states resilience in academic context refers to student's ability to deal with adversity and challenges in academic settings (Cited in Abram-Terry, 2014). The findings of this study also showed that resilience has significant relationship with autonomous learning and it is a strong predictor for autonomy.

Considering characteristics of resilience people such as goal-oriented, self- efficacy, adaptability to changes and adversity, having control over various choices, owning the sense of commitment (Kobasa, 1979; Rutters, 1985) from the literature and autonomous learner such as motivated, independent individual who choose purpose, goals, contents and process ( Krashen \& Seliger, 1975; Holec, 1983) researcher concluded that resilience individuals and autonomous learner have various characteristics in common. Statistical results in this study also revealed that there is a strong correlation between resilience as personality factor and autonomous learning.

The results of descriptive analysis rejected the first null hypothesis and the findings showed that there is a significant and positive relationship between EFL learners' resilience and autonomy. The results of multiple regression also showed that the second null hypothesis was rejected and there is a significance difference in predictability of EFL learners' resilience with autonomy. The findings also depicted that resilience can be a good predictor of autonomy. These findings align with results of Fahim and Kamali (2011) study that showed there are significant relationship among EFL learners' resilience, critical thinking and reading comprehension. The results showed that resilience of EFL 
learners could impact their process of learning. And, as resiliency increases it might make learners to be more autonomous. Findings of this study also are in line with other studies (Abbott, Klein, Hamilton \& Rosenthal, 2009; Bovier, Chamot \& Perneger, 2004) that showed resilience of EFL learners could impact their process of learning.

In addition, the results based on this study depict several implications for EFL learners, teachers and syllabus designers. Based on findings of this study improvement of resilience in learners may facilitate the process of learning. These finding have implications for teachers and syllabus designers to encourage learners to improve their resilience and also give learners more responsibility of their own learning process. Syllabus designers also can design second language materials and syllabus in a way that enables learners to be independent in learning process in a way to strengthen and improve their ability of resilience.

\section{References}

Abbott, J. K. (2009). The impact of online resilience training for sale managers on wellbeing \& work performance. Electronic Journal of Applied Psychology: General Articles (5), 89-95.

Abram-Terry, M. (2014). Academically Resilient English Language Learners: A Focus Group Study Exploring Risk Factors \& Protective Factors. Retrieved from http://scholars.compass.vcuedu/etd.

Benson, P. (2001). Teaching and researching autonomy in language learning. London: Longman .

Best, J. W. \& Kahn, J. V. (2006). Research in education (10th Ed.). Boston: Pearson Education Inc.

Bovier, P. , Chamot, E. \& Perneger, T.V. (2004). Perceived stress, internal resources, \& social support as determinations of mental health among young adults. Quality of Life Research (13), 161-170.

Chambers, R., Browley, A., \& Castille, C. (2014). Examining the validity of the resilience quotient . Retrieved from https://ncurdb.cur.org/ncur/2014

Connor, K., \& Davidson, J. (2003). Development of a new resilience scale: Connor \& Davidson resilience scale (CDRISC). Depression \& Anxiety (18), 76-82.

Fahim, M., \& Kamali, Z. (2011). The relationship between critical thinking \& their resilience level facing unfamiliar vocabulary in reading. Journal of Language Teaching \& Research , 2 (1), 104-111.

Herrman, H., Stewart, D. E., Diaz-Granados, N., Berger, E. L., Jackson, B., \& Yuen, T.(2011). What is resilience? The Canadian Journal of Psychiatry, 56(5), 258-265.

Holec, H. (1981). Autonomy in foreign language learning. Oxford: Pergamon.

Kobasa SC. (1979). Stressful life events, personality, and health: an inquiry into hardiness. Journal of Personality, Sociology Psychology 37,1-11.

Martin, A. J., \& Marsh, H.W. (2006). Academic resilience and its psychological and educational correlates: A construct validity approach. Psychology in schools , 43 (3), 267-281.

Mousapour Negari, G. \&. (2013). The relationship among autonomy, thinking styles \& language learning strategy use in Iranian EFL learners. International Journal of Linguistics , 5(1), 332-347.

Nation, I.S.P., \& Macalister, J. (2010). Language curriculum design . NewYork: Routledge.

Reivich, K., \& Shatte, A. (2002). The resilience factor: 7 essential skills for overcoming life's inevitable obstacles. Broadway Books.

Reynolds, W. M., \& Miller, G.E. (2003). Handbook of psychology, educational psychology (Vol. 7). (I. B. Weiner, Ed.) Hoboken, New Jersey: John Wiley \& Sons, Inc.

Rivers W. M. (1981). Teaching foreign language skills, 2nd edition. Chicago: University of Chicago Press.

Rutter, M. (1985). Resilience in the face of adversity: protective factors and resistance to psychiatric disorders. Journal of Psychology (147), 598-611.

Spratt, M., Humphreys, G., \& Chan, V. (2002). Autonomy \& motivation: which comes first? Language Teaching Research, 6 (3), 245-266.

Tabachnick, B. G., \& Fidell, L. S. (2007). Using multivariate statistics. Boston, MA: Pearson Education, Inc.

Wagnild, G. M. \& Young, H.M. (1993). Development and pscyhometric evaluation of the resilience scale. Journal of Nursing Measurement.

Wang, J. (2009). A study of resiliency characteristics in the adjustment of international graduate students at american universities. Journal of Studies in International Education (13), 22-45. 